DOI: $10.20472 / S S 2015.4 .1 .007$

\title{
THE USE OF SOCIAL NETWORK SITES FOR THE EMPLOYMENT SEEKING PROCESS
}

\section{TOM SANDER, PHOEY LEE TEH, BIRUTA SLOKA}

\begin{abstract}
:
Social networks are becoming more and more important in employment seeking process. The importance of social networks in this respect has been researched also in academic research worldwide and discussed on scientific conferences. The aim of the paper is to analyse the experience of the use of social network sites (SNS) with empirical results of 28 interviews with employment seeking individuals to identify the behaviour of employment seeking individuals and to identify further information regarding the employment seeking process in SNSs. In addition is an objective of the paper to falsify the dimensions of Sander / Teh. That the framework of the dimensions can be used to investigate SNSs and to describe the social capital theory of SNSs (Sander \& Teh 2014a). The importance of real social networks are presented in many papers but the perspective of the employment seeking individual in SNSs needs further and deeper research.
\end{abstract}

\section{Keywords:}

social network sites; employment seeking process, social capital theory

\section{Authors:}

TOM SANDER, University of Latvia, Germany, Email: Stud.tom.sander@fh-kufstein.ac.at PHOEY LEE TEH, Sunway University, Malaysia, Email: phoeyleet@sunway.edu.my BIRUTA SLOKA, University of Latvia, Latvia, Email: biruta.sloka@lu.Iv

\section{Citation:}

TOM SANDER, PHOEY LEE TEH, BIRUTA SLOKA (2015). The use of Social Network Sites for the Employment Seeking Process. International Journal of Social Sciences, Vol. IV(1), pp. 100-108., 10.20472/SS2015.4.1.007 


\section{Introduction}

The internet changed the society and provides new opportunities and risks for individuals. The infrastructure to communicate is increased and provides new opportunities. That changes the life of individuals and creates a new kind of societies and culture (Mandarano et al. 2011). The employment seeking process is heavily influenced by the creation of SNSs. The SNSs provides access to information and resources which can be used by applicants and companies. This paper concentrates on the employment seeking individuals if they are aware that they can use SNSs for the employment seeking process and if they are using SNSs. The impact of SNSs on employment seeking individuals and influence of social capital in this case needs further research efforts (Suphan et al. 2012)(Sander \& Teh 2014b).

The aim of this paper is to use expert interviews to explore the behaviour and causal mechanism of SNSs, to give an overview about the use of SNS member for employment seeking process. The behaviour of employment seeking individuals is of interest for organizations to identify suitable candidates for them. The knowledge about employment seeking individuals, their behaviour and use of SNSs gives organizations the opportunity to improve their recruiting processes and to identify new opportunities.

The second point of the current research is the social capital theory. It describes the social capital theory, as in which parts of SNSs mechanism and given as the operation of SNSs. It describes the social capital theory the SNSs, which parts of the SNSs mechanism can be explained with the social capital theory and which kind of explanations are given with the social capital theory for the operation of SNSs. This is tested with the dimensions of Sander / Teh and gives a first impression about the usefulness to explain SNSs with the social capital theory and to demonstrate the advantages and disadvantages of SNSs.

The importance of social networks for the identification of open positions and to get a new employment has been described in many articles (Granovetter 1995)(Leana \& van Buren III 1999) (Obukhova \& Lan 2012). The new circumstances are SNSs with new conditions for the society. Marsden has once cited the research question, on the improvement of employment seeking process with SNSs (Marsden 2001). The mentioned above findings of other researchers are inspirations for further empirical research which in some extent is covered in the paper.

\section{Social Networks}

Social networks are a minimum group of three individuals who are connected with each other with a tie. SNS are defined as a technical platform which provides the opportunity to communicate and to present resources to the SNS audience. The exchange of resources is mainly electronically. The size of social networks is increased because the technology enables the organisation and creation of large networks. The SNS are global and they have their own culture, rules and aims (Boyd \& Ellison 2007) (Caers \& Castelyns 2010). 
Individuals are living in social networks. They have three dimensions of social networks around them, the social network in which they are involved and participate, the network they know but they do not participate in this network and the unknown networks. That means individuals can only use for their advantages networks they are participate or they have to try to get access to known networks. That are the two kinds of networks they can use to identify a suitable position for them or to have an advantage. The focus of the paper are concentrated on the SNSs, in terms of which individuals already used and which are online available. The SNS is a part of the social networks in which the individual is involved and influence the daily life of the individual (Olugin Olguin et al. 2009).

The real social network memberships are limited by the resources of the network members. SNS as a new kind of social networks decrease the needed resources to participate in social networks. This is a new chance for individuals to take part in networks and to use networks.

Employment seeking people are in a difficult personal situation. They need employment to have an income and the prestige of unemployed individuals suffer in the society. This is a special situation and the result of the employment seeking process change the life of the individuals heavily. The support of real social networks to identify employment has been described by many authors but the differences between social networks and SNS need deeper investigations. This can create new knowledge to improve the employment seeking process with the novel opportunity of SNS to identify employment opportunities. Under consideration has to be the existence of many other opportunities to identify employment opportunities. The different media and tools to identify employment opportunities are in competition to SNS. Individuals are using the tools from which they expect to get the valuables result (Obukhova \& Lan 2012) (Suphan et al. 2012) (Feuls et al. 2014) (Krug \& Rebien 2012). Those are important theoretical findings developed by the authors in the current paper and will be developed also in future.

\section{Social Capital Theory}

The social capital theory explains the mechanism of relationships in networks. The networks are knots and connect individuals with each other. Social networks enable collective action and sharing of information or resources. The members of networks have advantages and disadvantages. The main mechanism of social networks is to maintain friendship, exchange information and resources, create prestige of network members and provide access to needed resources. The structure and position of individuals can be part of the social capital theory. Networks have different kind of ties with a different importance for the individual. SNS creates new circumstances for the network theories and social capital theory e.g. reduce transaction costs of information and resources (Williams 2007). The employment seeking process with the support of other network members has been deeply researched with real networks. The influence of the membership of social networks and the use of social networks to support the employment seeking process has negative and positive 
results. The research falsified the social capital theory for SNS. The technology changed the society and created SNS which are different to real networks and provides new opportunities and risks for the individual and society (Hampton 2004) (Lin 2001) (Burt 2000)(Wallis et al. 2004) (Mandarano et al. 2011). The mentioned above theoretical findings are developed in the current paper.

\section{Methods}

The expert interviews are used to get detailed information about causal mechanism and to explore information which is not access able with quantitative research methods. This paper contains the results of 28 expert interviews. The interviews have been collected with students at the University of Ludwigshafen. The interviews has been structured and guided to guarantee the same level of content and to avoid overseeing issues (Qu \& Dumay 2011). The employment seeking individuals who participated in the interviews are registered at SNS and use regularly SNS since several years (Liebold \& Trinczek 2009). This is a qualitative research to explain the behaviour and use of SNS for the employment seeking process. The answers has been categorized and interpreted (Züll \& Mohler 2001)(Mayring 2000). The questionnaire has been pretested with students to improve the results and to minimize misunderstandings (Sander \& Teh 2014c). The participation in SNS depends on different demographical variables (Suphan et al. 2012). The education and the higher the education as higher is the use of SNS (Statistisches Bundesamt 2014) and the education has an impact of social capital. The positive social capital depends of the level of education. The higher the education the higher is the positive social capital (Wolf 2009) (Krug \& Rebien 2012). The empirical results of the current research are presented in figure 1 and following results of empirical research.

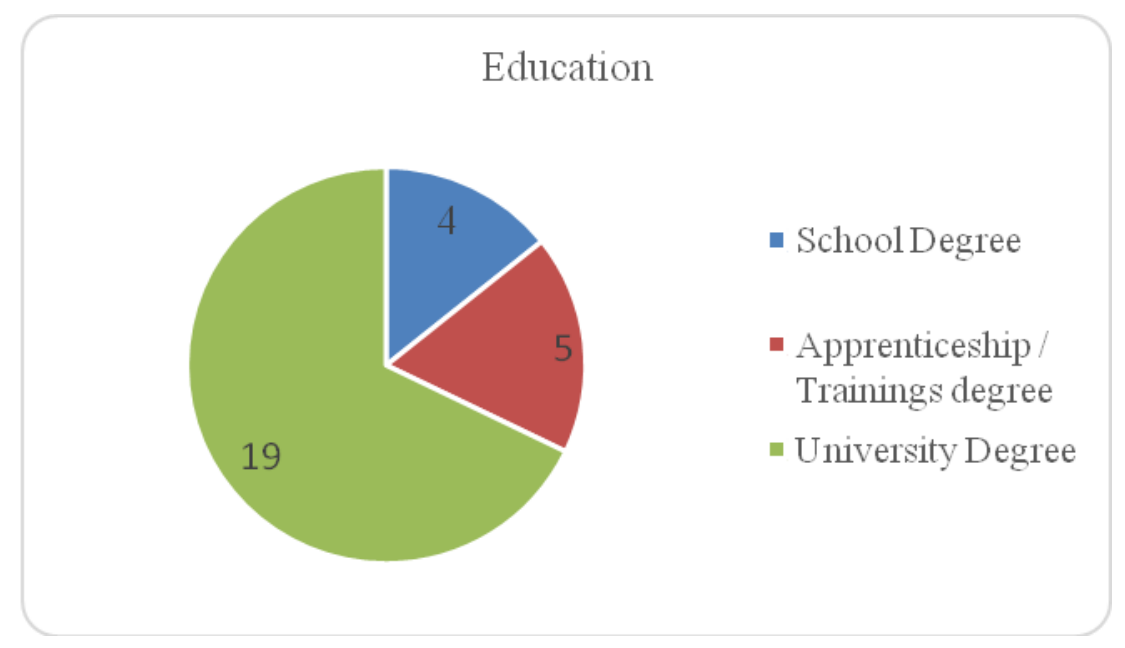

Figure 1 Distribution of the respondent's education

Source: Results of expert interviews by Tom Sander, 2014

Further has been 11 woman and 17 men participate in the expert interview and the age distribution gives the indication that the results are mainly suitable for individuals who are at the beginning of their career. 


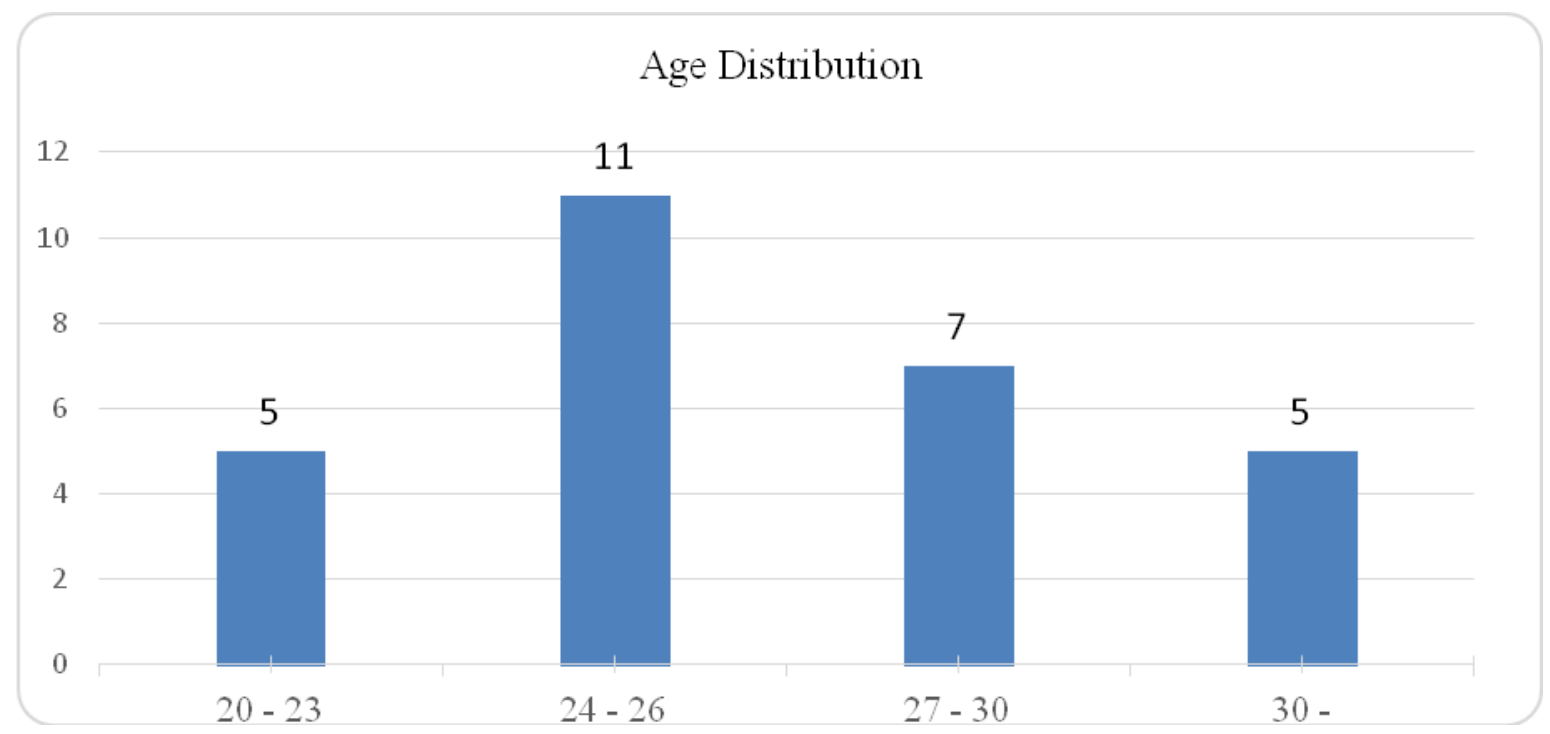

Figure 2 Distribution of the respondent's by age

Source: Results of expert interviews by Tom Sander, 2014

Data of the empirical research indicates that more interested are people in age group $24-26$ who are finalising their education.

\section{Analysis of the Data}

The first question has been regarding the use of SNS to identify the behaviour of employment seeking individuals. The result has been that some of the participants use SNS to support the application process. They use SNS to identify open positions or to contact other individuals to get further information. The important point is that the support of SNSs to identify employment opportunities compared with other reasons is small. The diagram below explains the main points and gives the indication that the employment seeking process is only a little part of the activities of individuals to identify specific information about employment opportunities. The exchange of information and maintain friendship is an important point for individuals to use SNSs. Twenty-Eight percent of the participants give the feedback that the reduced efforts to identify or to get information is an advantage of SNSs.

Why are you using social network sites?

Support for the application process

Exchange of information

9

Maintain Friendship

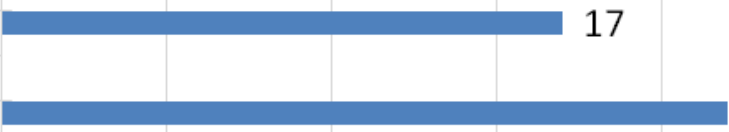

$\begin{array}{llllll}0 & 5 & 10 & 15 & 20 & 25\end{array}$

\section{Figure 3 Reasons to use SNSs}


Source: Results of expert interviews by Tom Sander, 2014

Sander / Teh identify in the social capital theory the exchange of information and maintain friendship as a dimension of social capital. The results give a first indication that social capital exist in SNSs (Sander \& Teh 2014c).

The reason of not using the SNSs for employment seeking process were further explain as following; Firstly, it refers to the important of their data protections, whereby $33,6 \%$ of the participant are concern about their personal data. This indicates that that SNS members are aware that their data in SNSs has to be protected. This issue can be one reason that people are not using SNSs for the employment seeking process. Supported is this result of data protection with the questions regarding negative issues in relation with SNS. Thirty-Six point four percent of the participants mention that they suspect that the internet can publish undesired people to non-authorized individuals. The information can damage the individual and create a disadvantage for them. Another explanation is that wrong information is presented in SNS. Eleven point two percent of the participants answer that they are frighten that SNSs are misused for wrong information and that wrong information can be forwarded fast and easy. It concludes the similar result of Wolf (2009), whereby in his statement "Faked information about individuals can have a negative impact for the employment seeking process". The employment seeking individuals are aware that the transparency and reduction of privacy with SNSs is a danger for the employment seeking process and themselves. That reduce their readiness to present details in SNSs. This results can explain the reason for the unattractiveness of SNS to identify employment opportunities, to use SNS to present to an audience personnel information and that SNS are not actively used to identify employment opportunities. That demonstrates that trust is important for SNS to provide information and to take part in social networks. Sander / Teh have described trust as an important issue in social capital theory with the mechanism of the social capital theory can be operated. This trust is not given from employment seeking individuals in SNS and can be an indication that the social capital theory has difficulties to explain the employment seeking process in SNS. 


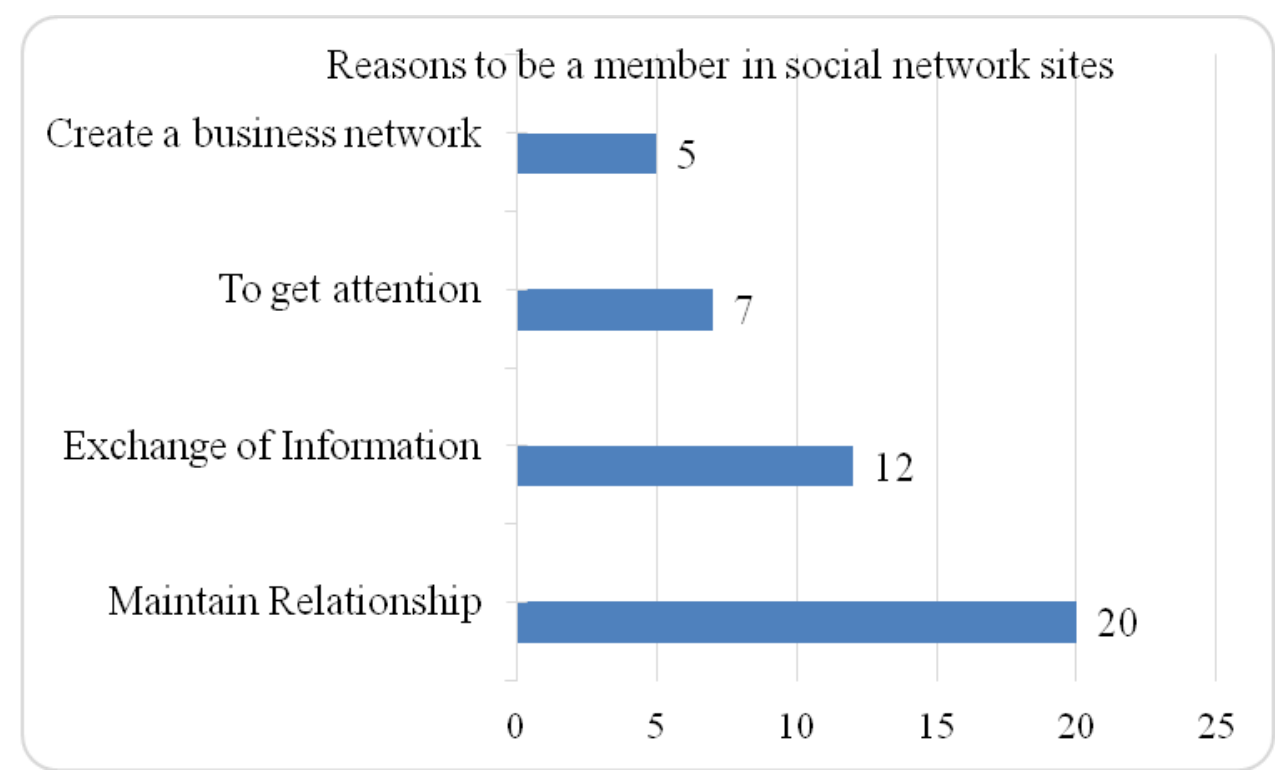

\section{Figure 4 Reasons to be member in a SNS}

Source: Results of expert interviews by Tom Sander, 2014

Further explains the expert interviews the reasons of individuals to be member of SNS. That gives further information regarding the employment seeking process because only $14 \%$ said that the SNSs can be used to create a business network. It appears that the SNS members are not aware to use the SNSs for business reasons or to explore employment opportunities. The main reason is to maintain friendship and to exchange information. The use of SNS is for communication and information important for the SNSs participants.

\section{Conclusion}

The results give a first indication that SNS are mainly used to exchange information and to maintain friendship. The use of SNS for the employment seeking process exist but is not the main reason for individuals to use SNS. The advantages of SNS is to communicate effectively with friends and to gain information without large efforts.

The first impression with the analysed data is the limited importance of SNS for the employment seeking process of SNS members. The registered members of SNS mainly are not using SNSs to identify employment opportunities or limit personal information about them to avoid negative impact. This first information is an important issue which has to be under consideration for the employment seeking process.

The negative aspects are mentioned by the participants is data protection and the distribution of negative or wrong information. That can be one reason not to use SNSs and is an indication for the trust of individuals in SNSs.

The results of employment seeking individuals compared with the analysed data of the students which has been collected with the pre - test for this study demonstrates some differences between this two populations and confirm that individuals use their social networks for their advantage dependent of their situation. 
The dimensions from Sander / Teh have been proved and need further quantitative support. This qualitative results give a first indication and explains the reasons for the use or none use of SNS for the employment seeking process. The next steps have to be the quantitative research to get more representative results. This first step gives an insight which needs further efforts.

\section{References}

Boyd, D.M. \& Ellison, N.B., 2007. Social Network Sites: Definition, History, and Scholarship. Journal of Computer-Mediated Communication, 13(1), pp.210-230.

Burt, R.S., 2000. The network structure of social capital R. I. Sutton \& B. M. Staw, eds. Research In Organizational Behavior, 22(May), pp.345-423.

Caers, R. \& Castelyns, V., 2010. Linkedln and Facebook in Belgium: The Influences and Biases of Social Network Sites in Recruitment and Selection Procedures. Social Science Computer Review, 29(4), pp.437-448.

Feuls, M., Fieseler, C. \& Suphan, A., 2014. A social net? Internet and social media use during unemployment. Work, Employment \& Society, pp.1-20.

Granovetter, M.S., 1995. Getting a job 2nd ed. Gran, ed., Chicago: The university of Chicago press.

Hampton, K.N., 2004. Networked sociability online, off line. In E. Elgar, ed. Network society, a cross cultural perspective. Cheltenham: Castells, Manuel, pp. 217 232.

Krug, G. \& Rebien, M., 2012. Network-Based Job Search. Zeitschrift für Soziologie2, $41(4)$, pp.316 - 333 .

Leana, C.R. \& van Buren III, H.J., 1999. ORGANIZATIONAL SOCIAL CAPITAL AND EMPLOYMENT PRACTICES. Academy of Management Review, 24(3), pp.538555.

Liebold, R. \& Trinczek, R., 2009. Experteninterview. In S. Kühl, P. Strodtholz, \& A. Taffertshofer, eds. Handbuch Methoden der Organisationsforschung. Wiesbaden, pp. $32-56$.

Lin, N., 2001. Building a network theory of social capital. In N. Lin, K. Cook, \& R. Burt, eds. Social capital theory and research. New Jersey, pp. 3 - 30.

Mandarano, L., Meenar, M. \& Steins, C., 2011. Building Social Capital in the Digital Age of Civic Engagement. Journal of Planning Literature, 25(2), pp.123-135.

Marsden, P. V., 2001. Interpersonal Ties, Social Capital, and Employer Staffing Practices. In N. Lin, K. Cook, \& R. S. Burt, eds. Social Capital, Theory and Research. London: Aldine Transaction, pp. 105 - 127. 
Mayring, P., 2000. Qualitative Inhaltsanalyse. Forum: Qualitative Sozialforschung, 1(2).

Obukhova, E. \& Lan, G., 2012. Do Job-Seekers Benefit from Contacts? A WithinIndividual Test with Contemporaneous Searches. Management Science, 59(10), pp.2204 - 2216.

Olugin Olguin, D. et al., 2009. Sensible Organizations: Technology and Methodology for Automatically Measuring Organizational Behavior. Cybernetics, 39(1), pp.43 -55 .

Qu, S.Q. \& Dumay, J., 2011. The qualitative research interview. Qualitative Research in Accounting \& Management, 8(3), pp.238-264.

Sander, T. \& Teh, P.L., 2014a. A Concept to Measure Social Capital in Social Network Sites. International Journal of Future Computer and Communication, $3(2)$.

Sander, T. \& Teh, P.L., 2014b. A Method to Identify Research Gaps in the Literature for the Social Capital Theory for Social Network Sites under Consideration of the Employment Seeking Process. In RISEBA Conference. Riga.

Sander, T. \& Teh, P.L., 2014c. Determining the Indicators of Social Capital Theory to Social Network Sites. In 3rd Inenatinal Conference on User Science and Engineering. Shah Alam, Malaysia.

Statistisches Bundesamt, 2014. Erhebung über die private Nutzung von Informationsund Kommunikationstechnologien, Wiesbaden.

Suphan, A., Feuls, M. \& Fieseler, C., 2012. Social Media's Potential in Improving the Mental Well- being of the Unemployed. In K. Eriksson-Backa, A. Luoma, \& E. Krook, eds. Exploring the Abyss of Inequalities. Berlin Heidelberg: Springer, pp. $10-28$.

Wallis, J., Killerby, P. \& Dollery, B., 2004. Social economics and social capital. International Journal of Social Economics, 31(3), pp.239-258.

Williams, D., 2007. The impact of time online: social capital and cyberbalkanization. Cyberpsychology \& behavior: the impact of the Internet, multimedia and virtual reality on behavior and society, 10(3), pp.398-406.

Wolf, C., 2009. Netzwerke und soziale Unterstützung, Mannheim.

Züll, C. \& Mohler, P.P., 2001. Computerunterstützue Inhaltsanalyse: Codierung und Analyse von Antworten auf offene Fragen, Mannheim. 